\title{
Impacts of using cartoons as an instructional tool on English communicative skills of young learners at a Vietnamese primary school
}

\author{
Le Thi Thuy Nhung ${ }^{1 *}$, Tran Doan Vuong Dieu ${ }^{2}$ \\ ${ }^{1}$ Banking University of Ho Chi Minh City, Vietnam \\ ${ }^{2}$ Ho Chi Minh University of Technology, Vienam \\ *Corresponding author: nhungltt@buh.edu.vn
}

\begin{abstract}
ARTICLE INFO
ABSTRACT

DOI: $10.46223 / \mathrm{HCMCOUJS.}$

soci.en.10.2.553.2020

Received: June $20^{\text {th }}, 2020$

Revised: November $30^{\text {th }}, 2020$

Accepted: December $15^{\text {th }}, 2020$

Keywords:

authentic materials, cartoons, English as a second/foreign language, teaching tool

This study examined the impact of the use of cartoons on the speaking and listening skills of students in a primary school in a rural area in Vietnam and their attitudes towards the use of cartoons as a learning tool in their English classes. The study employed an experimental research design to collect data. Participants included 70 fifth-graders divided into two groups, the control group and the experiment group. The control group was taught regular English lessons. The experiment group learned similar lessons but cartoons were added to the English lesson to practice speaking and listening skills for six weeks. Before and after the experiment, the speaking and listening skills of the two groups were measured by a pretest and a posttest. In addition, the students in the experiment group were surveyed using a questionnaire to examine their attitudes towards watching cartoons for learning purposes. The findings show the English speaking and listening skills of the students in the experimental group improved more significantly than those of the students in the control group. Besides, the students in the experiment group expressed positive attitudes towards watching cartoons in English classes. The findings had implications for English language teachers at primary schools in Vietnam and in other non-dominant English speaking countries to include visual materials in their English lessons to enhance young learners' English proficiency.
\end{abstract}

\section{Introduction}

Media have been utilized both in real life and in the classroom for language learning purposes because they provide learners with access to authentic language in a meaningful and motivational way. Media offer students realistic and practical language learning experience through the medium of task-based activities, in-class projects and creative tasks (Nunan, 1991). The use of media helps to stimulate and engage learners. In addition, media enable students to gain a better understanding of culture, and language that traditional approaches to foreign language education often fail to provide (Brown, 2001).

Cartoons, a popular form of media, have been used in language education as an instructional tool to enhance the language proficiency of young learners. The use of animated cartoons in the language classroom has exerted positive impacts on learners' L2 language 
performance with regard to language skills and test scores. Cartoons are regarded as an effective source of authentic language input for young learners (Clark, 2000; Doring, 2002).

In Vietnam, thanks to the rapid development of technology in language education, cartoons have been introduced into the English teaching programs at elementary levels for several years. The use of cartoons for teaching purposes appears more prevalent in cities rather than in rural areas where teaching facilities are often inadequate and teachers are less technologically knowledgeable. However, the effect of using cartoons for English teaching purposes in Vietnam has not been investigated empirically. To fill the gap, the present study aims to provide insights into the use of different audiovisual tools, particularly cartoons as authentic input for young learners of English. More specifically, the study will provide empirical evidence on the effect of cartoons on the English language proficiency of primary school students in Vietnam.

\section{Aims of the study}

This study aims to find out the extent to which the use of cartoons in English class would enhance the speaking and listening skills of students at a primary school in a rural area of a Southern province of Vietnam. The study also explores students' perceptions of the use of cartoons as an instructional tool for English learning purposes.

\section{Research questions}

This study aims to answer the following research questions:

1. To what extent does the use of cartoons in English classes enhance the English speaking and listening skills of students in Tran Dai Nghia primary school?

2. What are students' attitudes towards the use of cartoons in English classes?

\section{Literature review}

There is a variety of authentic teaching materials available to EFL/ESL teachers to utilize to serve different learning needs in different educational settings. While social interaction as a source of authentic language input is not available in the EFL context, other sources of authentic language input using audiovisual aids such as songs, movies, and cartoons are widely used for language learning purposes. Particularly, cartoons have been employed as a tool to improve the language skills of young learners. Previous research has highlighted the pedagogical values of cartoons as an instructional tool for EFL teachers in language classrooms in different educational contexts.

\subsection{Use of cartoons an instructional tool for the language classroom}

According to Oxford Dictionary, cartoons are movies that use a series of motion pictures rather than real people to tell stories. Cartoons can be played via devices such as televisions, computers, smartphones and laptops (Horby, 1995). Cartoons are considered as an effective educational tool for young learners to learn English for several reasons. Previous research shows that using cartoons in language teaching not only improves students' language skills but also increases young learners' motivation for learning languages. Watching cartoons helps students to understand subject matters, memorize vocabulary and learn grammatical structures more effectively (Lin, Chen, \& Dwyer, 2006; Sarko, 2008). Also, cartoons including scenes, real conversations of characters and props tend to engage students more easily than text materials do (Canning-Wilson, 2000; Clark, 2000). Young students tend to be more interested in learning English through cartoons than learning with printed books (Fata \& Wahuyni, 2016). The authentic language used in cartoons can help students to relate the classroom language with the authentic 
language in real life communication (Nunan, 1999). In addition, cartoons can help to create a positive classroom environment and increase interaction between students and teachers and among the students. The use of cartoons in a language classroom can reduce students' stress and anxiety (Kirkgoz, 2011).

Cartoons provide both visual and audio materials and thus enable students to understand the content of the story better than audio materials alone. Watching cartoons enables students to listen to characters as well as watch their movements simultaneously. Furthermore, cartoon stories tend to relate to young students' lives. Students can imitate the body language and voices of cartoon characters and model them for real-life communication (Rice, 1993). They are able to remember the language spoken by cartoon characters more easily. As a result, young learners are able to improve their speaking and listening skills via watching cartoons (Kirkgoz, 2011).

Several studies have investigated the use of cartoons in teaching at the primary level. Cartoons were shown to exert a positive impact on students' vocabulary learning (Karakas \& Saricoban, 2012) and there was evidence of students' vocabulary expansion through watching cartoons in English class (Kayaoglu, Akbas, \& Oztruk, 2011). In addition to an increase in vocabulary knowledge, watching cartoons can enhance students' overall language skills (Algilasi, 2010), especially their grammar and vocabulary knowledge (Arikan \& Taraf, 2010). Cartoons also increased students' motivation and interest in language learning (Pranatha, 2005).

Research into the use of cartoons as a source of authentic material in language teaching provides limited empirical evidence. Most previous studies looked into the effects of cartoons on vocabulary learning and grammatical knowledge of young learners. There was little evidence of the impacts of cartoons on students' listening and speaking skills among primary school students. In addition, prior research employed qualitative methods to investigate the effects of cartoons on language learning including classroom observation and interviews while quantitative methods such as experiments were rarely adopted. In order to fill this gap, this research was conducted using mixed methods to examine the extent to which cartoons developed young learners' communicative skills with a focus on listening and speaking skills.

\section{Methodology}

This study employed an experimental research design to find out whether the use of cartoons in English class would improve the English speaking and listening skills of primary school students. The use of mixed methods including the pretest, post-test, and survey questionnaire helped the researcher to corroborate the findings from different data sources to answer the research questions.

\subsection{Research setting}

This research was conducted at a primary school located in a Southern province of Vietnam in the academic year of 2018-2019 where the second researcher has been working as a teacher of English for more than five years. As a public institution, the school in the study follows the English teaching curriculum prescribed by Vietnam's Ministry of Education and Training. The English program at the school used the textbook series Family and friends in which four language skills are integrated into each lesson. Due to the washback of English testing at several public schools in Vietnam which tend to focus on students' reading comprehension and grammar, English teachers in the school in the study tended to concentrate on teaching reading and writing skills while the two other skills were neglected in their English classes. As a result, most students were likely to be better at reading and writing than at listening and speaking skills. Many young students at several public schools in rural areas are not familiar with communicating orally in English. 


\subsection{Sample and sampling procedures}

A purposeful sampling technique was employed to select participants for the study. This technique allows researchers to identify and select information-rich cases related to the phenomenon of interest and enables researchers to create generalizations from the data. As a full time teacher at the school, the second researcher was given permission to conduct the study by employing students of her own classes.

In the study, fifth-graders were selected as participants as they were mentally and linguistically more mature to understand the content of cartoons better than junior students. A total of 70 fifth graders from two classes took part in the study. There were 35 students in the experimental group and 35 students in the control group. The students had similar levels of English proficiency as they were placed in their current classes based on their scores in the placement test at the start of the school year. The students in the two classes were regarded as high-performing students at English as they gained better scores compared to the rest of the fifth graders in the school at the time of this study.

Both groups were given the pre-test before the experiment and the post-test after the experiment. The control group was taught lessons in the book series Families and friends for fifth graders. The experimental group learned English lessons using the same textbooks and cartoon watching activities were added to their regular English classes. Six cartoons were shown to the students during the experiment including Doraemon (Stand by me episode), The Lion King, Ratatouille, Lady and the Tramp, Frozen, and Hotel Transylvania. Each cartoon lesson lasts about 30 minutes in total. Both groups were instructed by the second researcher as their teacher of English.

\subsection{Research instruments}

\subsubsection{Pre-test}

In this study, the pre-test and post-test were used to compare the performance of students with regard to their speaking and listening skills before and after the experiment. Two weeks into their second term, the students in the study were asked to take the pretest to measure their English proficiency. The pretest included listening and speaking components. The listening test included 10 multiple choice questions that check students' listening comprehension of the cartoon after they watched. The speaking test asked students to tell a story using cue cards about the cartoon they watched. The students in both control and experiment groups watched a cartoon taken from the Doraemon series in English and were asked to complete the test afterward. To measure students' speaking performance, a marking rubric adapted from Heaton (1990) was used. There were four criteria in an analytic rubric including content, fluency, grammar and vocabulary. Students' performance was rated using a scale from 1 to 5 .

\subsubsection{Post-test}

The posttest was similar to the pretest with regard to format and level of difficulty. The listening test consists of 10 multiple choices closed questions and the speaking test required students to tell the content of the cartoon using the given cue cards about the cartoon they had watched.

\subsubsection{Questionnaire}

The questionnaire included seven multiple-choice closed questions. Question 1 asks students about the frequency of watching cartoons. Question 2 and 3 ask students about the number of English words students learned after watching each cartoon. Question 4 asks the reason why 
students can remember words and sentences. Question 5 and 6 elicit students' opinions about learning English via cartoons in English class. Question 7 asks students' motivation to watch cartoons in English class. The questionnaire was translated into Vietnamese to ensure clarity and accuracy in students' comprehension of the content.

\subsubsection{Data collection procedures}

Both groups completed the pretest a week before the experiment. A cartoon entitled Phineas and Ferb was selected for the pretest. Then, the students were tested on their listening comprehension of the story in the cartoon.

The control group and the experimental groups were taught regular lessons using the Family and friends book series, a special edition. For the experimental group, cartoon watching activities were added to the regular lessons as extra practice. For the experiment group, at the beginning of the cartoon watching session, the researcher introduced the cartoon characters to the students using cue cards. The students were pre-taught some vocabulary and phrases which they would hear from the cartoon. Then the students watched the cartoon twice and completed the listening comprehension exercises such as short answer questions, matching, true, or false afterward. Speaking activities asked students to tell a story using the cue cards about the cartoon they had watched.

After the six weeks experiment, both groups of students completed the posttest to see if there was any improvement in their speaking and listening proficiency. For posttests, the students watched an episode from Doraemon cartoon series and then answered comprehension questions about the cartoon. To ensure the validity and reliability of the listening test, both groups were checked orally to make sure that the students in the study had not previously watched the cartoon.

For the speaking test, due to time constraints and students' willingness to participate, 15 students from each group were invited to complete the speaking test. The students were given a set of cue cards about the cartoon and were individually asked to tell a story based on the cues given. Each student had five minutes to prepare the story and told a story for about three minutes. In order to explore the students' attitudes towards the use of cartoons in English class, survey questionnaires were administered among 35 students in the experimental group after taking part in the experiment. Both pretest and posttests were marked by the researcher using the rating scale of ten for listening tests and a scale of five for the speaking tests.

\section{Findings}

\subsection{Students' speaking performance}

To examine whether using cartoons in English classes could improve students' speaking and listening skills, data from the pretest and posttest were used. Students' mean scores in speaking tests from both groups before and after the experiment were compared using paired sample t-tests. To provide answers to the research questions, the data obtained from the pretest and post tests were analyzed. The following table show the results of both groups with regard to students' scores on the pretest and posttest. 


\section{Table 1}

Results of students' speaking test performance

\begin{tabular}{|c|c|c|c|c|c|c|c|c|}
\hline \multirow[t]{2}{*}{ Group } & \multicolumn{3}{|c|}{ Pretest scores } & \multicolumn{2}{|c|}{$\begin{array}{c}\text { Posttest } \\
\text { scores }\end{array}$} & \multirow[b]{2}{*}{$t$} & \multirow[b]{2}{*}{$D f$} & \multirow[b]{2}{*}{$p$} \\
\hline & $\mathrm{N}$ & $M$ & $S . D$ & $M$ & $S . D$ & & & \\
\hline Experiment group & 15 & 58 & 5.91 & 65.6 & 7.03 & 2.6 & 28 & $0.013^{*}$ \\
\hline Control group & 15 & 58.3 & 6.17 & 62 & 4.55 & & & \\
\hline
\end{tabular}

$*_{\mathrm{p}}<0.05$

Source: Data analysis result of the research

The results of the speaking tests show that there was no statistically significant difference between the mean scores of the experiment group $(M=58)$ and the control group $(M=58.3)$ in the pretest. However, the mean scores from the post-test by the experimental group $(\mathrm{M}=65.6)$ were higher than the mean scores of the control group $(M=62)$. To examine if there was any statistical difference in mean scores of both groups in the post test, the T-test was used. The results show that there was a statistically significant difference between the experimental group and the control group in their speaking performance in the post test $(M(E G)=65.6, M(C C)=62, p=0.013)$. In other words, the use of cartoons in English classes was shown to improve students' speaking skills of the experimental group.

The students' performance in both tests was presented visually in Figure 1 below.

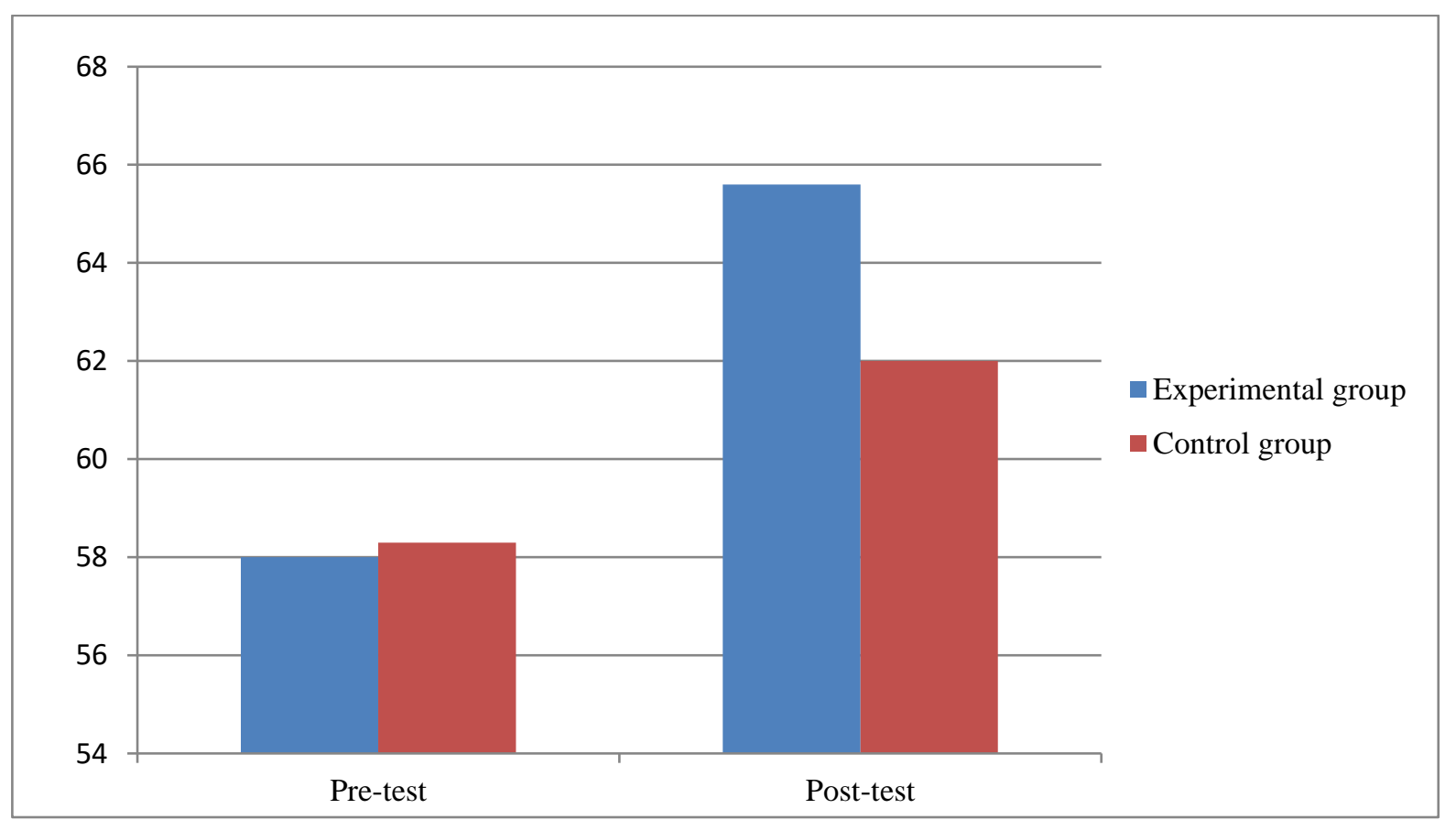

Figure 1. Students' speaking performance on pretest and posttest

\subsection{Results of students' listening performance}

To examine if there was any difference in students' performance in the listening tests between the two groups, a t-test was conducted and the results were reported in Table 2. 


\section{Table 2}

Results of students' listening performance

\begin{tabular}{|c|c|c|c|c|c|c|c|c|}
\hline \multirow[t]{2}{*}{ Group } & \multicolumn{3}{|c|}{ Pretest Scores } & \multicolumn{2}{|c|}{ Posttest Scores } & \multirow[b]{2}{*}{$t$} & \multirow[b]{2}{*}{$d f$} & \multirow[b]{2}{*}{$p$} \\
\hline & $\mathrm{N}$ & $M$ & $S D$ & $M$ & $S D$ & & & \\
\hline Experimental group (EG) & 35 & 67.1 & 8.9 & 89.4 & 7.2 & \multirow[b]{2}{*}{3.74} & \multirow[b]{2}{*}{68} & \multirow{2}{*}{$0.0003^{*}$} \\
\hline Control group (CC) & 35 & 65.4 & 9.8 & 80 & 8.7 & & & \\
\hline
\end{tabular}

*p $<0.05$

Source: Data analysis result of the research

The results indicate that the mean scores of the experimental group and the control group improved after learning English through watching cartoons for six weeks. The mean scores of the experimental group in the post-test $(\mathrm{M}=89.4)$ were significantly higher than their scores in the pretest $(M=67.1)$. Besides, the mean score of the control group in the post-test $(M=80)$ was also higher than their scores in the pre-test $(M=65.4)$.

To examine if there was any significant difference in listening performance in the posttest between the two groups, a t-test was used. The results show that there was a statistically significant difference in their listening performance between the two groups $(\mathrm{M}(\mathrm{EG})=89.4 ; \mathrm{M}(\mathrm{CC})=80$, $\mathrm{p}<0.05)$. The mean score of the experimental group was significantly higher than that of the control group. It suggests that watching cartoons could improve students' listening comprehension in English of the experimental group.

\subsection{Students' attitudes toward watching cartoons}

The data obtained from the questionnaire survey among the students in the experimental group were analyzed and reported using themes.

\subsubsection{Frequency of watching cartoons in English at home}

When asked about how often the students watched cartoons at home on a weekly basis, some students reported watching cartoons once a week, while others watched cartoons on a daily basis. About half of the students in the survey claimed that they watched cartoons more than twice a week.

\subsubsection{Increase in vocabulary knowledge after watching cartoons in English}

The students reported an increase in vocabulary items they could remember after watching cartoons. They even learned some short expressions from cartoon characters. They could be able to learn by heart certain words and expressions because the teacher asked them to repeat them many times during the lessons. Some students remember new vocabulary and sentences because they sounded fun to them.

\subsubsection{Students' positive attitudes towards watching cartoons in English classes}

The results showed that all students in the survey liked watching cartoons in English classes. Watching cartoons in English classes was both for entertainment and practicing the speaking skill. 


\section{Discussion}

The findings show that using cartoons in English classes improved students' speaking and listening performance. The experimental group scored significantly higher than the control groups in both skills. There was a statistically significant difference in listening and speaking skills between the students who watched cartoons in English class and the students who did not. In addition, learning English through watching cartoons helps foster students' positive attitudes towards learning English.

The findings from this study confirmed the benefits of cartoons as an efficient learning tool for students to enhance their language skills. The students were able to develop their vocabulary knowledge, listening and speaking skills. After watching cartoons, the students could be able to memorize words and sentences they learned from the cartoons. They were able to understand and retell a story after watching cartoons. Previous research confirms the pedagogical value of cartoons in enhancing students' competence in using the target language (Nunan, 1999), especially in developing students' speaking skill (Fata \& Wahyuni, 2016).

In addition, the use of cartoons in the English class enhances students' motivation and positive attitudes towards learning English. Many students enjoyed learning English through watching cartoons and they felt more eager, excited and willing to take part in classroom activities. They felt more relaxed and confident to ask and answer the questions during English lessons. Furthermore, the use of cartoons also encouraged students to actively participate in classroom activities and thus increased their motivation of learning a language. These findings are also reinforced by previous studies (Brown, 2001; Clark, 2000).

\section{Implications}

The results of this research confirm the pedagogical values of cartoons as a source of authentic language input which could support young students' development of language skills. Therefore, English teachers should take into consideration the following factors when using cartoons for English lessons. First, teachers should make use of cartoons as effective learning materials to better engage students in English class. However, cartoons should be carefully selected to achieve learning purposes. Due attention should be paid to the quality of the cartoons to ascertain that they are well integrated into the content of the text book or language learning programs. Also, choice of cartoons should take into account students' language level and interest. More importantly, language teachers should be trained both technologically and pedagogically in order to optimize the benefits of this source of authentic language input in language education.

\section{References}

Algilasi, M. A. (2010). The effects of using text and picture animation on promoting English learning among students of the 5th grade. Palestine: Hebron University.

Arikan, A., \& Taraf, H. (2010). Contextualizing young learners' English lessons with cartoons: Focus on grammar and vocabulary. Educational Leadership, 2(2), 5212-5215.

Brown, H. D. (2001). Teaching by principles: An interactive approach to language pedagogy. San Francisco, CA: Pearson.

Canning-Wilson, C. (2000). Practical aspects of using videos in the foreign language classroom. Retrieved April 20, 2020, from http://iteslj.org/Articles/Canning-Video.html 
Clark, C. (2000). Innovative strategy: Concept cartoons. Instructional and Learning Strategies, 12, 34-45.

Doring, A. (2002). The use of cartoons as a teaching and learning strategy with adult learners. New Zealand Journal of Adult Learning, 30(1), 56-62.

Fata, I. A., \& Wahyuni, S. (2016). Cartoon: Media in promoting students speaking skill in Aceh. The 1st EEIC in Conjunction with the 2nd Reciprocal Graduate, 1(2), 169-172.

Horby, A. S. (1995). Oxford advanced learners dictionary. New York, NY: Oxford University Press.

Karakas, A., \& Saricoban, A. (2012). The impact of watching subtitled animated cartoons on incidental vocabulary learning of ELT students. The Journal of Teaching English with Technology, 12(4), 3-15.

Kayaoglu, M. N., Akbas, R. D., \& Ozturk, Z. (2011). A small scale experimental study: Using animations to learn vocabulary. TOJET: The Turkish Online Journal of Educational Technology, 10(2), 24-30.

Kirkgoz, Y. (2011). Implementing cartoon movie recorded speaking tasks. The Turkish Online Journal of Educational Technology, 10(4), 1-13.

Lin, H., Chen, T., \& Dwyer, M. (2006). Effect of static visuals and computer generated animations in facilitating immediate and delayed achievement in EFL classroom. Foreign Languages Annals, 39(2), 203-207.

Nunan, D. (1991). Research methods in language learning. Cambridge, MA: Cambridge University Press.

Nunan, D. (1999). Second language teaching and learning. Boston, MA: Heinle \& Heinle.

Pranatha, A. N. (2005). A study on teaching vocabulary by using cartoons at second grade. Retrieved April 22, 2020, from http://eprints.umm.ac.id/267/1/A_Study_on_Teaching_ Vocabulary_By_Using_Cartoon_at_Second_Grade_2F_of_SLTP_6_Serang.pdf

Rice, A. M. (1993). Teaching with videos. New York, NY: MacMillan.

Sarko, R. (2008). Teaching English vocabulary to children by using pictures and cartoon videos: A comparative study at Sdncilubang ii, Bogor, Gunadarma University. Retrieved April 25, 2020, from http://www.gunadarma.ac.id 
